\title{
Our Errant Epistemic Aim
}

\author{
STEPHEN MAITZEN
}

Dalhousie University

Often the first issue addressed by a theory of justified belief is the aim, goal, purpose, or objective of epistemic justification. ${ }^{1}$ What, in short, is the point of epistemic justification? Or, to put it a bit differently, why value justification: why is it worth having or pursuing? ${ }^{2}$ Prominent epistemologists, including both externalists and internalists, have proposed (or sometimes just assumed) the following answer: the ultimate aim of epistemic justification is to maximize true belief and minimize false belief. This answer specifies what I'll call the "nominal aim," an aim that gets endorsed (sometimes with qualifications) by a number of well-known accounts of justification. William Alston, an externalist with certain internalist scruples, ${ }^{3}$ is among the most explicit champions of the nominal aim:

Epistemic evaluation is undertaken from what we might call the "epistemic point of view." That point of view is defined by the aim at maximizing truth and minimizing falsity in a large body of beliefs.... [O]ur central cognitive aim is to amass a large body of beliefs with a favorable truth-falsity ratio. For a belief to be justified is for it...to be awarded high marks relative to that aim.... [A]ny concept of epistemic justification is a concept of some condition that is desirable or commendable from the standpoint of the aim at maximizing truth and minimizing falsity....4

1 I will be using "goal," "aim," "purpose," "point," and "objective" interchangeably, since I take the concept $I$ have in mind to be captured by any of those terms. Just the same, I am happy to speak instead of the "value of justification" or the "reason that justification is valuable," in case one finds talk of the "aim of justification" uncongenial (see note 2).

2 In correspondence, William Alston has objected to the notion that justification, i.e. the status of being justified, has an aim, since, unlike activities, statuses do not typically have aims. I'm therefore content to speak of the value of justification and to understand claims about its aim as claims about its value.

3 For details on Alston's hybrid view of justification, see "An Internalist Externalism," in Alston (1989), 227-45. In the remainder of this paper I will focus on Alston's theory of justification, not because I find it uniquely problematic but principally because Alston is such an explicit proponent of the nominal aim; his theory, then, serves as a natural illustration of its perils.

4 "Concepts of Epistemic Justification," in Alston (1989), 81-114; 83-84. Alston reaffirms the nominal aim in Alston (1991: 74): "[J]ustifiably believing is believing in 
Elsewhere Alston speaks of "the most basic cognitive aim: to believe what is true and not to believe what is false." $\mathrm{He}$ endorses the nominal aim, presumably, as a natural way of cashing out this most basic cognitive goal.

Alston is hardly alone here. Keith Lehrer, a thoroughgoing internalist, also appears to endorse the nominal aim when he discusses "the objective of justification, to wit, accepting something if and only if it is true."6 Even if Lehrer's objective isn't expressed in the "maximizing"/"minimizing" terms of the nominal aim, it surely amounts to the same thing. For one's accepting propositions if and only if true will have the effect of maximizing one's true beliefs and minimizing (indeed, to zero) one's false beliefs. Even an imperfect tendency to accept propositions if and only if true will tend to serve the nominal aim; the closeness of approach to the goal will obviously depend on the strength of the tendency. Many epistemologists seem to endorse, at some level, the nominal aim, although not all of them are as explicit about it as Alston and Lehrer.

In spite of its endorsement by noted theorists, the nominal aim makes trouble, I'll try to show, for theories of justification which adopt it. Stated as the goal of epistemic justification-or as the reason we value justificationit generates plainly unacceptable consequences for our evaluation of beliefs. Indeed, the nominal aim is misguided, I'll contend, even when qualified in the ways its proponents typically propose. I won't propose here a replacement for the nominal aim, but I will suggest that we need to look elsewhere if we want to know what makes epistemic justification worth having.

\section{Rules, Extensional Equivalence, and the Nominal Aim}

What happens to the epistemic evaluation of beliefs if we adopt the nominal aim-if, that is, we take to heart the view that epistemic justification aims ultimately to maximize true belief and minimize false belief? If the nominal aim is the reason for having, or pursuing, justification, then it ought to follow that beliefs are justified insofar as they serve the nominal aim and unjustified insofar as they do not. But this consequence gives rise to an obvious problem. If justification is essentially a matter of serving the nominal aim, then it seems we would evaluate no true belief as unjustified and no false belief as justified, no matter how the beliefs were formed or sustained. The reason is straightforward. If one seeks, above all else, to maximize the number of true (and minimize the number of false) beliefs in one's (presumably large) stock of beliefs, then adding one more true belief surely counts as serving that goal, while adding a false belief surely counts as disserving it. As long

a way that is valuable vis-à-vis the aim at maximizing true belief and minimizing false belief."

5 “A 'Doxastic Practice' Approach to Epistemology," in Clay and Lehrer (1989), 17.

6 Lehrer 1990: 82. 
as true rather than false beliefs get adopted, we in fact approach the goal; from the standpoint of the nominal aim, it becomes irrelevant just how the beliefs are formed or sustained.

This reasoning may seem fishy-an impression I hope to dispel in due course-but it is not, at any rate, idiosyncratic. In a daring recent paper, Crispin Sartwell uses similar reasoning but arrives, I think, at the wrong conclusion. ${ }^{7}$ To put it roughly, Sartwell argues that knowledge and true belief are indistinguishable as the goals of inquiry, and he concludes, on that basis, that knowledge and true belief are identical. Knowledge, on his view, never requires more than mere true belief. While a handful of more orthodox theorists, including Alston, have allowed that knowledge needn't always entail justification, that sometimes unjustified true beliefs amount to knowledge, Sartwell's claim is stronger: a belief's counting as knowledge never, let alone not always, requires anything more than its truth. I think Sartwell has embraced the wrong horn of the dilemma. He seems to have followed the nominal aim to one of its odd conclusions, but instead of discarding the nominal aim he accepts the conclusion: knowledge is merely true belief. No amount of loyalty to the nominal aim should force one to bite the bullet that hard.

The nominal aim, as I said before, also appears to count all and only true beliefs as justified. But this result surely conflicts with our settled intuitions concerning epistemic justification. If epistemologists, including Sartwell, agree on anything, it's that the epistemic justification of beliefs depends not just on the truth or falsity of the beliefs but, primarily, on the way in which they are formed or sustained. The nominal aim, therefore, must get something about justification wrong.

Similar charges have, of course, been brought against classical act-utilitarian theories in ethics. Act-utilitarianism has the consequence, which many have found implausible, that acts which maximize utility are always justified, no matter what the agent's motives in performing them. Rule-utilitarianism emerged at least partly in response to this implausible result. ${ }^{8}$ But its critics have questioned (1) whether rule-utilitarianism is consistent with the goal of all forms of utilitarianism (namely, maximizing utility) and (2) whether any rule-utilitarianism consistent with that goal doesn't just collapse into act-utilitarianism. $^{9}$

Consider the well-known thesis that rule- and act-utilitarianism are extensionally equivalent. ${ }^{10}$ According to that thesis, roughly, any kind of rule-

Sartwell (1992).

8 Many, of course, take the implausible consequences of act-utilitarianism to refute utilitarianism of any kind.

9 For a detailed account of such criticisms, see Lyons (1965).

10 Lyons (1965) contains the seminal presentation of the extensional equivalence argument. 
utilitarianism that actually serves the utilitarian goal (i.e. that actually maximizes utility) will have the very same evaluative consequences as pure actutilitarianism. The two versions of utilitarianism are, as they say, extensionally equivalent: their judgments of any act will always agree. As David Lyons remarks, after a long and careful analysis of "simple" (act) and "generalized" (rule) utilitarianism,

acts have (a) desirable effects if, and only if, they have desirable tendencies; (b) undesirable effects if, and only if, they have undesirable tendencies... Hence there is no substantive choice between [the simple and the generalized] kinds of utilitarianism. ${ }^{11}$

The epistemic analogue is straightforward: we simply evaluate beliefs rather than acts. Let us say that a belief has, in Alvin Goldman's term, a "verific" effect just in case it serves the nominal aim and that it has a verific tendency just in case it tends to serve the nominal aim. (Let's not worry right now about what a verific tendency could be.) It follows, then, from extensional equivalence that a belief will have a verific effect if and only if it has a verific tendency. A belief will tend to serve the nominal aim, in other words, if and only if it serves the nominal aim.

Therefore, if, as Alston holds, the nominal aim governs epistemic justification, no instance of true belief will fail to be justified unless it tends not to maximize true belief and minimize false belief. For any true proposition $p$, S's believing that $p$ at $t$ will be justified, unless somehow that belief tends not to maximize S's total stock of true beliefs. But how could S's belief at $t$ of some true proposition fail to maximize, at $t$, her total stock of true beliefs? Indeed, how could it have anything but a verific tendency? Suppose that $S$ already has some finite number of true beliefs at (or just before) $t$, although $p$ is not (yet) among the true propositions she believes. Suppose, further, that S's doxastic alternatives at $t$ consist of believing $p$, believing not- $p$, believing some proposition $q$ contrary to $p$, and suspending judgment on whether or not $p$. Only by believing $p$ will S maximize, at $t$, her total stock of true beliefs, for believing $p$ is her only verific alternative at $t .^{12}$

In sum, then, S's believing that $p$ at $t$ will be justified unless somehow it tends not to maximize, in the long run, her stock of true beliefs. But without much more argument, I can't see how S's belief at $t$ of an arbitrary true proposition could have such a tendency. And even if S's believing some particular truth does tend, in the long run, to disserve the nominal aim, that tendency surely won't hold for S's true beliefs in general. In general, true beliefs will both serve the nominal aim and tend to do so; thus they will come out as justified on any standard defined by the nominal aim. False beliefs, by the

11 Lyons 1965: 115, 118.

12 By speaking in terms of S's "doxastic alternatives," I do not mean to take a stand on the degree to which $S$, or anyone, has voluntary control over her beliefs. 
same token, will come out as unjustified unless somehow they tend to serve the nominal aim. In both cases, epistemic justification will have little, if anything, to do with the way in which beliefs are formed or sustained; it will turn, instead, merely on the truth-value (or, perhaps, the content) of the beliefs. Thus, Alston's tendency condition does no real work; despite appearances to the contrary, it does nothing, or nearly nothing, to avoid the implausible consequences of adopting the nominal aim.

Granted, I have assumed that one can be said to maximize one's total stock of true beliefs at $t$ by believing some true proposition at $t$. But that assumption seems plausible. I see no relevant difference between choosing the optimific action from among one's ethical alternatives and "choosing" (so to speak) the verific "action" from among one's doxastic alternatives. Again, one's doxastic alternatives may be just as rich and varied as the alternatives faced by the utilitarian deliberator; they can include believing some true proposition $p$, believing its negation, believing a contrary proposition $q$, believing some more informative proposition $r$ (i.e. a true proposition that entails $p$ but isn't entailed by $p$ ), or suspending judgment on $p$ altogether. If it makes sense to speak of an agent's maximizing utility at $t$, then it should make sense to speak of a subject's maximizing her true beliefs at $t$. Indeed, if we adopt the epistemic aim, similar to the nominal aim, of maximizing the information content of one's beliefs, the analogy becomes even tighter: given that aim, one should "choose," from among one's doxastic alternatives, the belief yielding the greatest information content (just as the utilitarian recommends choosing the action yielding the greatest utility). ${ }^{13}$ This epistemic aim would, for example, enjoin believing the more informative proposition $r$, mentioned above, over its less informative but equally true cousin, $p$. I do not for a moment recommend this doctored version of the nominal aim, since I suspect it also leads to unacceptable results. I introduce it only to illustrate the intelligibility of maximizing one's true beliefs at $t$ by believing truly at $t$.

One familiar rebuttal to my argument goes as follows. As the ultimate goal of justification, the nominal aim was never meant to apply directly to beliefs but, instead, to the mechanisms that generate beliefs. Properly understood, the justification of beliefs doesn't depend on their serving the nominal aim; it depends on whether the mechanisms which form beliefs serve (or tend to serve) the nominal aim. Serving (or tending to serve) the nominal aim is a criterion for acceptable belief-forming methods, mechanisms, or processes; it's not a criterion that justified beliefs must (or can) meet directly. ${ }^{14}$ In a

13 I owe this point to Carl Ginet.

14 It is interesting to note that Alvin Goldman (1986) considers criteria such as truthmaximization primarily in application to rules (or systems of rules) for epistemic justification. I think this fact shows that he does not adopt, straightforwardly, the nominal aim (nor, I should stress, does he claim to). Compare also Sosa (1980), who 
similar way, betting-rules are rational insofar as they (tend to) maximize one's gains and minimize one's losses; we don't, however, assess the rationality of individual bets by that criterion. Properly applied to doxastic mechanisms, rather than to beliefs themselves, the nominal aim generates no implausible consequences.

But our reply is almost as obvious as this rebuttal. For starters, the rebuttal just reasserts the generic distinction between, for example, maximizing utility directly and following rules that tend to maximize utility. That distinction supposedly avoids implausible results in the ethical case and in the epistemic case as well. But I've already argued that the elevation of utilitarian rules over utility-maximization itself is prima facie inconsistent with the goal of all utilitarian theories. More important, I've suggested that the distinction (between classical act-utilitarianism and optimific rule-utilitarianism) in fact collapses; the two forms of utilitarianism are extensionally equivalent. If one nevertheless prefers a truly distinctive form of rule-utilitarianism, it shows that one has adopted a different goal: the goal, perhaps, of following a manageable set of rules which tend to maximize utility, or the goal of stable, predictable, generally optimific behavior by moral agents, or some such thing. Whatever the goal, it will differ from the goal of maximizing utility as such.

The epistemic case is exactly analogous. Either (a) the rule-version of a nominal aim theory is inconsistent with (b) regarding the nominal aim as the raison d'être of justification, or else the distinction between (a) and (b) collapses. If one nevertheless insists on applying the nominal aim only to doxastic rules (or mechanisms), it shows one's commitment to a goal different from the nominal aim: the goal of forming beliefs only by way of reliable mechanisms, perhaps. Whatever the goal, it will differ from the nominal aim, and one ought to own up to that fact. Moreover, contrary to the rule fetishist, I see no reason in principle why the nominal aim must apply to doxastic rules rather than to beliefs. (Of course, in both cases it leads to unacceptable results, but that is obviously not a principled difference between them.) Why, for instance, must a maximization-criterion apply only to betting-rules and not directly to bets? I don't begrudge the rule fetishist her fetish; she can adopt whatever epistemic goal she wants, but she ought to be honest about it. Either her goal will differ from the nominal aim, or else it will share the nominal aim's untoward consequences.

This fact suggests another line of response to the obvious rebuttal. Assuming that, for instance, Alston's repeated endorsement of the nominal aim is deliberate and not inadvertent, he has simply mistaken the nominal aim for

suggests that "primary justification" attaches to "intellectual virtues, to stable dispositions for belief acquisition," and that "secondary justification" attaches to "particular beliefs in virtue of their source in intellectual virtues." 
the epistemic aim he really adopts. Such a mistake would be understandable, given the initial plausibility of the nominal aim: it sounds so obviously sensible as the goal of justification. But faced with the consequences of the nominal aim, Alston's theory (including its tendency condition) is better understood as adopting, say, the goal of forming beliefs only by way of reliable mechanisms, or some such thing. At any rate, goes the reply, Alston, et al., are not to be read as adopting the nominal aim, whatever their claims to the contrary. I find this sort of reply congenial, since it forsakes the nominal aim in favor, perhaps, of something less burdened with counterintuitive features, but I won't pause here to evaluate or endorse the reply.

\section{Conclusion}

We have seen that theories which adopt the nominal aim have implausible consequences for epistemic justification. We have seen, too, that the blame pretty clearly falls on the nominal aim itself. This evidence suggests that we abandon the nominal aim in favor of an epistemic aim that we can really endorse, preferably an aim that our intuitions reveal we implicitly endorse already.

No doubt the nominal aim I have rejected derives much of its appeal from the undoubted fact that we human beings are, in an important sense, truthseekers. But, as I think I've shown, that fact does not settle the issue in favor of the nominal aim. To adopt the nominal aim as the goal of justification is, perhaps, to overstate the importance of our seeking truth; it is, at any rate, to draw the wrong lesson from the fact that we do seek truth. ${ }^{15}$

15 I wish to thank William Alston, Carl Ginet, Robert Pasnau, and Mark Owen Webb for helpful comments on earlier versions of this paper. 


\section{REFERENCES}

Alston, William P.

(1989) Epistemic Justification. Ithaca and London: Cornell University Press.

(1991) Perceiving God. Ithaca and London: Cornell University Press.

Clay, Marjorie, and Keith Lehrer (eds.)

(1989) Knowledge and Skepticism. Boulder: Westview Press.

Goldman, Alvin I.

(1986) Epistemology and Cognition. Cambridge: Harvard University Press.

Lehrer, Keith

(1990) Theory of Knowledge. Boulder: Westview Press.

Lyons, David

(1965) The Forms and Limits of Utilitarianism. Oxford: Oxford University Press.

Sartwell, Crispin

(1992) "Why Knowledge is Merely True Belief," Journal of Philosophy 89: 167-80.

Sosa, Ernest

(1980) "The Raft and the Pyramid: Coherence versus Foundations in the Theory of Knowledge," Midwest Studies in Philosophy 5: 3-25. 